\title{
Traumatic Brain Injuries during Development: Implications for Alcohol Abuse
}

\author{
Zachary M. Weil * and Kate Karelina \\ Behavioral Neuroendocrinology Group, Department of Neuroscience, Center for Brain and Spinal Cord Repair, Ohio State \\ University Wexner Medical Center, Columbus, $\mathrm{OH}$, United States
}

Traumatic brain injuries are strongly related to alcohol intoxication as by some estimates half or more of all brain injuries involve at least one intoxicated individual. Additionally, there is mounting evidence that traumatic brain injuries can themselves serve as independent risk factors for the development of alcohol use disorders, particularly when injury occurs during juvenile or adolescent development. Here, we will review the epidemiological and experimental evidence for this phenomenon and discuss potential psychosocial mediators including attenuation of negative affect and impaired decision making as well as neurochemical mediators including disruption in the glutamatergic, GABAergic, and dopaminergic signaling pathways and increases in inflammation.

Keywords: alcohol, traumatic brain injury, dopamine, inflammation, adolescent

\section{OPEN ACCESS}

Edited by:

Jacqueline M. Barker, Medical University of South Carolina,

United States

Reviewed by:

Firas H. Kobeissy, University of Florida, United States Aleksei Yurievich Egorov, Institute of Evolutionary Physiology and Biochemistry (RAS), Russia

*Correspondence: Zachary M. Weil zachary.weil@osumc.edu

Received: 24 April 2017 Accepted: 07 July 2017 Published: 20 July 2017

Citation:

Weil ZM and Karelina K (2017) Traumatic Brain Injuries during Development: Implications for Alcohol Abuse.

Front. Behav. Neurosci. 11:135 doi: 10.3389/fnbeh.2017.00135

\section{INTRODUCTION}

Traumatic brain injuries (TBI) have received tremendous scientific and public attention in recent years. This attention is commensurate with the enormous societal and economic costs associated with a condition that affects millions of Americans and because of underreporting is likely even larger than current estimates. One important insight that has become clear is that TBIs are more than discrete events but are the start of a lifelong process comprising recovery, adaptation, and vulnerability to a large variety of other disease states (Masel and DeWitt, 2010; Corrigan and Hammond, 2013). In particular, children and adolescents who suffer TBI are less likely to finish school and maintain employment and suffer a greater risk of neurological and psychiatric disorders (among many others; Corrigan et al., 2013).

Alcohol is a prominent component of TBI. A recent assessment of the U.S. national trauma registry revealed alcohol use to be present in as many as 50\% of all TBI-related emergency department visits (Chen et al., 2012). Not surprisingly alcohol use in general and binge drinking in particular are powerful risk factors for TBI (Savola et al., 2005; Vaaramo et al., 2014) and contribute substantially to mortality of TBI patients (see reference Opreanu et al., 2010 for a review). Critically, the use of alcohol in patients recovering from TBI is highly deleterious and there is significant evidence that patients that drink after TBI have poorer cognitive, neuropsychiatric and occupational outcomes than those that do not (Corrigan, 1995; Weil et al., 2016a; Unsworth and Mathias, 2017). Drinking after TBI is associated with poor long term outcomes in a variety of domains (Corrigan, 1995). Similar results have been reported in experimental TBI, for example we recently reported that administration of binge-like levels of alcohol in adulthood produces significant functional and neuropathological impairments in mice that had experienced TBI as juveniles (Karelina et al., 2017). Given that both past TBI and drinking are risk factors for future 
TBI and repeated TBI tend to produce much more severe damage (Guskiewicz et al., 2000; Giza et al., 2013; McCrory et al., 2013) reducing drinking behavior in this patient population will serve to both improve outcomes and reduce the possibility of devastating future injuries.

The strong epidemiological association between brain injuries and pre-injury drinking mean that the TBI population is composed disproportionately of heavy drinkers. However, there is emerging clinical and experimental evidence that TBI may serve as an independent risk factor for the development of alcohol use disorders (AUDs; Weil et al., 2016a; Merkel et al., 2017a). This is particularly apparent among patients that suffer TBIs during childhood or adolescence. The TBI-induced increase in alcohol abuse among patients that suffer injuries during development likely reflects both a greater vulnerability of the developing nervous system to disruption by injury and that children are less likely to already be problem drinkers at the time of their injuries, and thus it is easier to detect independent contributions of TBI to the development of AUDs (Weil et al., 2016a).

\section{DRINKING IN TBI PATIENTS}

The relationship between TBI and alcohol abuse is well-known but had been considered to be unidirectional, i.e., drinking was a risk factor for head injuries. The possibility that the opposite was also true, i.e., that brain injuries could under specific conditions increases drinking behavior, was obscured by several factors. First, problem drinking (particularly bingedrinking) is a key predictor and proximate cause of TBI (Corrigan and Mysiw, 2012). Therefore, the TBI population is made up disproportionately of heavy drinkers making it difficult to detect effects of TBI on later alcohol-related outcomes (Corrigan, 1995). Second, patients with the most severe injuries often reduce drinking during the first months after injury. This seems to occur because of a combination of factors but includes lack of access to alcohol because of physical disability and hospitalization (and inpatient rehabilitation; Bombardier et al., 2003). Third, most studies have examined individuals injured as adults but that represents both a relatively small proportion of the total population and includes individuals that have either already begun drinking or are past the age at which new AUD tend to emerge (Grant and Dawson, 1997). Finally, patients that begin (or resume) drinking after injury are more likely to be lost to follow up in longitudinal studies and thus the numbers of these individuals might be underestimated (Corrigan et al., 1997). Indeed, studies of post-TBI drinking in adults have most often reported that there is an initial decrease in alcohol intake followed by some patients gradually returning to problem drinking and others becoming abstainers (Kreutzer et al., 1996; Ponsford et al., 2007). Studies have produced conflicting reports as to whether adult injuries increase the rates of, or vulnerability to, AUDs (Bjork and Grant, 2009).

In contrast, early life injury has been consistently and repeatedly associated with the later development of AUDs (Weil et al., 2016a; Merkel et al., 2017a). For instance, high school students that suffered a TBI were more than twice as likely to meet the diagnostic criteria for AUDs after injury (Ilie et al., 2015). Further the earlier that injuries occur the stronger the association with substance abuse. Children injured before age five were more than 3.6 times as likely to exhibit substance abuse as teenagers than were uninjured children (McKinlay et al., 2014). Patients in an inpatient rehabilitation setting for TBI were more than twice as likely to meet the diagnostic criteria for substance abuse if they had experienced a previous injury before the age of 16 (Corrigan et al., 2013). In addition, among inmates in the South Carolina penitentiary system, age of first brain injury was associated with both severity and earlier age of onset of substance abuse (Fishbein et al., 2016).

A similar age of injury-related discrepancy in drinking after TBI has also been reported in animals. We recently reported that juvenile TBI, but not adult injury, significantly increased alcohol self-administration in a two-bottle choice paradigm in mice (Weil et al., 2016b). Other investigations of drinking behavior in animals injured as adults have produced conflicting results with some studies reporting increases and others reporting decreases (Lowing et al., 2014; Lim et al., 2015; Mayeux et al., 2015). Taken together, it seems that injuries that occur early in life are more likely to produce AUD, however, the specific mechanisms that link TBI to vulnerability to problem drinking remain unspecified.

\section{POTENTIAL MECHANISMS OF INCREASED DRINKING AFTER TBI}

In the next section we will discuss two very general classes of potential mediators that underlie the increased drinking behavior observed in pediatric brain injury patients (summarized in Figure 1). This is not intended to be an exhaustive discussion but rather to highlight some of the active areas of research.

\section{PSYCHOSOCIAL FACTORS}

TBI interacts with or exacerbates many of the traditional risk factors for AUD and may limit some of the moderating factors that serve to reduce AUD risk. Although, the individual contributions of these risk factors are likely relatively minor, when taken together they contribute to the increased likelihood of AUD in these patients. For example, many head injury patients have a family history of AUD, which results in both increased modeling of drinking behavior and genetic risk (Laucht et al., 2007). In addition, head injuries in pediatric populations are strongly, but often indirectly, associated with alcohol intoxication. In children and adolescents, vehicular accidents and physical violence are responsible for a substantial subset of injuries (though the exact percentages shift across age; Keenan and Bratton, 2006; Narang and Clarke, 2014) and extremely large percentages of head injuries related to assaults or incidences of physical abuse are associated with intoxication of either the injured child or more often the assailant, who is often a parent or other close relative (Kraus et al., 1989; Dube et al., 2001). A similar relationship exists for motor vehicle accidents where at least one participant is likely to be intoxicated (Stoduto et al., 1993). Further, male children are more likely to experience 


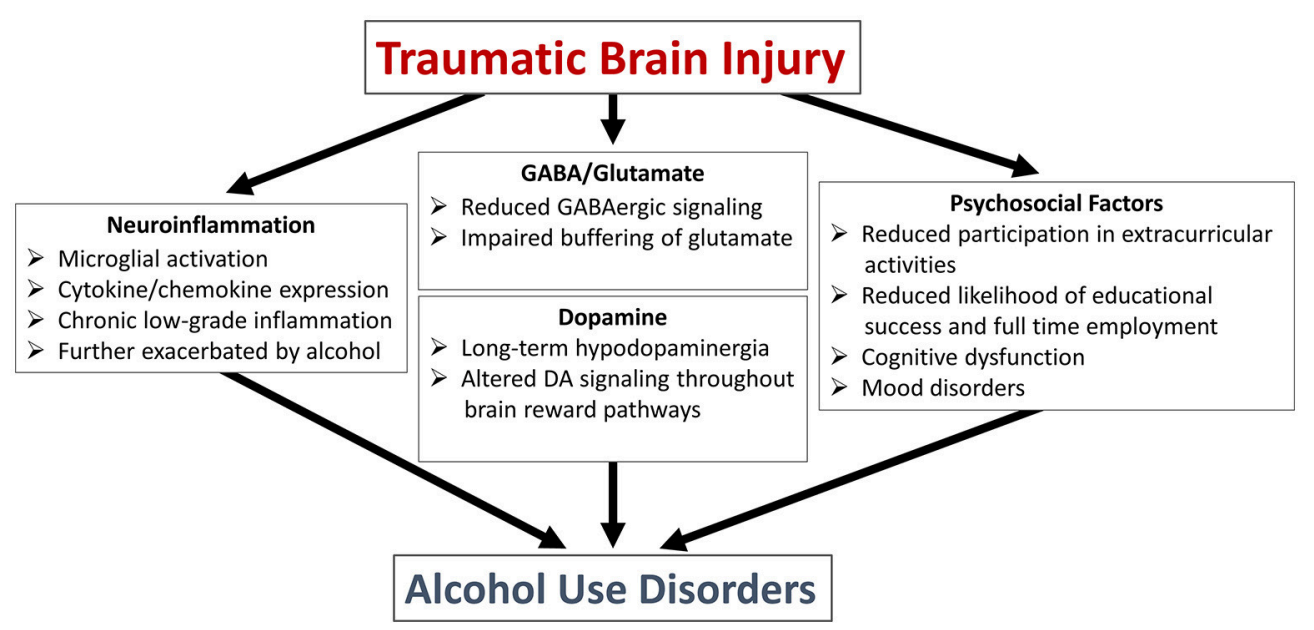

FIGURE 1 | Potential mechanisms linking traumatic brain injury to alcohol use disorders.

abuse-associated head trauma and are also at greater risk of later TBI and adolescent AUD (Costello et al., 1999; Narang and Clarke, 2014). Thus, the pediatric TBI population consists disproportionately of individuals from a family with alcohol use problems and/or a history of abuse, which are both critical risk factors for the development of AUDs (Dube et al., 2001; Barnow et al., 2002).

TBI also reduces many of the negative predictors of substance abuse. For instance, participation in extracurricular activities, forming stable romantic relationships, educational success, and full time employment are associated with reduced risk of alcohol abuse, yet all are less likely in brain injury survivors (StewartScott and Douglas, 1998; Corrigan et al., 2013). Further, more severe TBI is often associated with prolonged absence from school and long-term disability, which often results in alienation from peer groups and increased alcohol use (Glang et al., 1997; Maggs et al., 2008).

The decision to drink has been proposed to reflect a balance between potential negative consequences (hangover, relationship issues, health consequences etc.) and perceived gains (reducing social inhibitions, negative mood states etc.) (Goldman, 1994). TBI can influence both sides of that equation by both reducing the ability to perceive negative consequences and increasing the perception of gains to be derived from drinking. For instance, that framework, termed the incentive motivation theory (Goldman, 1994), would predict that individuals less able to foresee the future consequences of their actions would be more likely to elect to drink. Indeed, TBI survivors show deficits in delay discounting and other cognitive tasks that require evaluation of delayed consequences (Bechara et al., 1994; Kolitz et al., 2003; Graham and Cardon, 2008). Finally, TBI results in more general executive dysfunction that can manifest itself as impulsivity and reduced inhibition, which can serve as predictors of AUD (Laucht et al., 2007; Iacono et al., 2008).

The other component of the incentive motivation theory is that individuals perceive a benefit to drinking. This perceived benefit could be in the form of increasing mood state, or reducing negative emotions or pain, and thus serves as a form of selfmedication (King et al., 2004; Bolton et al., 2009). TBI survivors suffer from psychiatric sequelae including anxiety, depression and in a large subset of cases, post-traumatic stress disorder (PTSD; Breslau et al., 1991, 1997; Jorge et al., 2004). TBI often damages corticolimbic structures that regulate mood states, and endocrine and autonomic physiology as well as inducing long-term inflammatory responses, which can all increase the symptoms of affective disorders (Juengst et al., 2015). Even beyond direct damage to the nervous system, patients that acquire long-term cognitive or physical disabilities after brain injury often undergo a significant and prolonged period of adjustment to living with a disability (Smedema and Ebener, 2010). Thus, the very real possibility exists that brain injured patients are drinking to reduce the negative emotional states that are promoted by brain injury (Beresford et al., 2005).

\section{NEUROINFLAMMATORY SIGNALING}

The psychosocial and genetic risk factors associated with pediatric TBI also occur in the context of damage to the developing nervous system and likely disruptions of normal brain development. TBI is a complex pathophysiological process that can involve neuronal death, axon disconnection and degeneration, metabolic dysfunction, and aberrant neuroplasticity among other processes depending on the exact type and severity of the injury, comorbidities and age of the patient (Werner and Engelhard, 2007). However, one feature nearly universal to TBI is inflammation (Kelley et al., 2007; Ziebell and Morganti-Kossmann, 2010; Johnson et al., 2013). TBI both directly activates immune cells in the brain and primes cells such that future inflammatory stimuli produce exaggerated inflammatory responses (Fenn et al., 2014) and this is particularly true when inflammatory events occur early in life (Bilbo and Schwarz, 2009). The enhanced basal and stimulus-evoked immune responsiveness of the injured nervous system is important because there is a bidirectional relationship 
between neuroinflammation and alcohol intake (Kelley and Dantzer, 2011).

Alcohol produces a central inflammatory response characterized by activation of microglia and induction of inflammatory signaling and cytokines (Valles et al., 2004; Crews et al., 2011). Indeed the brains of long-term alcoholics exhibit evidence of prolonged low-grade inflammatory responses that may contribute to cognitive decline (He and Crews, 2008; Leclercq et al., 2014; Yen et al., 2017). The specific mechanism through which alcohol induces inflammatory responses is not fully understood but likely includes activation of the danger signal detecting molecules toll-like receptors (TLR; AlfonsoLoeches et al., 2010; Pascual et al., 2011). Critically, inflammation and components of inflammatory signaling drive drinking behavior (Crews et al., 2011). Mice treated with the bacterial cell wall component lipopolysaccharide (a molecule that induces a potent inflammatory response) self-administer significantly more alcohol (Blednov et al., 2011). Further, treatment with minocycline, a semisynthetic antibiotic with potent central anti-inflammatory activity produces a prolonged reduction in spontaneous alcohol self-administration (Agrawal et al., 2011). Mice lacking various components of inflammatory signaling cascades also drink less under basal conditions (Blednov et al., 2012).

Thus, TBI produces both acute inflammatory responses and primes immune cells like microglia to exhibit exaggerated inflammatory responses to other stimuli later in life. In this manner, TBI can establish a vicious cycle wherein inflammatory responses promote drinking behavior and subsequent drinking further exacerbates inflammatory responses (Mayeux et al., 2015). Critically, the alteration in inflammatory responses from alcohol occur in a brain already impacted by TBI and thus in addition to the deleterious consequences of heavy drinking that occur in otherwise healthy individuals, TBI patients face the potential of enhanced and chronic neuroinflammatory responses.

\section{NEUROCHEMICAL ABNORMALITIES}

Dysfunction in neuronal signaling after TBI, during development, can be roughly categorized into several etiologies. First, there is some (although often minimal) frank loss of neurons and associated axonal degeneration that directly disconnects or otherwise impairs neuronal connections. Additionally, as many critical neurodevelopmental events are occurring during these developmental epochs, TBI can result in disruption in the establishment of, or homeostasis in, neurochemical systems.

For instance, the ascending dopaminergic system undergoes significant functional and anatomical plasticity during late childhood and early adolescence (Philpot et al., 2009). This is characterized by changing tonic and stimulus evoked firing, alterations in synthetic machinery, transporter expression, and receptor distribution (Wahlstrom et al., 2010; McCutcheon et al., 2012). Importantly, this period of rapid neurodevelopment coincides temporally with vulnerability to substance abuse (Grant and Dawson, 1998). Early experience with drugs of abuse is a key risk factor for the development of substance abuse disorders and has been shown experimentally to alter the long-term function of the dopamine system (Guerri and Pascual, 2010).

Similarly, dysfunction in dopaminergic signaling is both a common consequence of TBI and a risk factor for the development of AUD (Martinez et al., 2005). There is a large body of experimental animal work indicating that dopamine physiology is significantly altered by TBI, with most studies reporting an acute hyperdopaminergia that resolves into a longterm hypodopaminergic state (Yan et al., 2001, 2002; Wagner et al., 2005a,b, 2009; Hutson et al., 2011).

Although, there is little direct evidence of dopaminergic dysfunction in human TBI patients (Donnemiller et al., 2000), drugs that enhance dopaminergic signaling (either by increasing synaptic dopamine or directly agonizing dopamine receptors) are relatively effective and part of the standard of care for reducing the cognitive deficits experienced by TBI patients (Neurobehavioral Guidelines Working et al., 2006; Bales et al., 2009; Huang et al., 2016). The utility of these drugs does not necessarily indicate that the dopamine system is hypofunctional in human patients (i.e., more dopamine may be helpful to improve cognitive outcomes in patients because of other neurological deficits) but the preponderance of evidence from clinical and experimental sources suggest some level of long term dysfunction in this system (Bales et al., 2009).

Critically, the alterations in dopamine signaling appear to occur beyond what would be expected from frank axonal degeneration or neuronal death (although damage to the ventral tegmental area and striatal targets have been reported following TBI; Dunn-Meynell and Levin, 1997; Ding et al., 2001; Hutson et al., 2011). Rather the alterations in dopamine signaling likely include alterations in network regulation and ongoing inflammation (Merkel et al., 2017a,b). Inflammatory signaling also serves to impair dopaminergic signaling and likely plays a role in the vulnerability to substance abuse in the brain-injured population (Felger and Miller, 2012). For instance, tyrosine hydroxylase production of L-Dopa is the rate-limiting step in dopamine biosynthesis. This enzymatic reaction requires the cofactor, tetrahydrobiopterin (BH4), which is also required for the synthesis of nitric oxide by nitric oxide synthases which are strongly upregulated by inflammatory signals meaning that BH4 can be shunted away from tyrosine hydroxylase when the brain is inflamed (Cunnington and Channon, 2010; Ono et al., 2010; Felger and Miller, 2012).

In contrast, surprisingly little is known about long-term adjustments in the glutamatergic and GABAergic systems after TBI. Acutely, TBI is associated with large, uncontrolled glutamate release that is a key factor in the damage associated with trauma (Katayama et al., 1990; Bullock et al., 1998). Further GABAergic neurons may be disproportionately likely to die and are overall less effective at balancing excitation. Finally, there is often persistent dysfunction in glial cells that typically buffer extracellular glutamate concentrations by expressing transporter proteins. Together, these lead to a net increase in excitatory signaling (Cantu et al., 2015) and the dysregulation in excitatoryinhibitory balance is very often associated with the development of post-traumatic epilepsy, particularly after pediatric injury 
(Ates et al., 2006; Pavlov et al., 2011). Over the long term there are compensatory changes that seem to buffer excess excitation but as a consequence of limiting excitatory neurotransmission may limit cognitive recovery (De Beaumont et al., 2012). This is evidenced by the consistent finding that TBI impairs the expression of long-term potentiation (Giza and Prins, 2006; Schwarzbach et al., 2006; Dorsett et al., 2017).

Like TBI, AUD are associated with disruption in the balance in excitatory-inhibitory balance and dysregulation of both glutamatergic and GABAergic signaling (Koob and Volkow, 2016). Alcohol both directly modulates activity of glutamate and GABA receptors, and can induce compensatory adjustments in these systems that perpetuate problem drinking (Chandler, 2003; Fitzgerald et al., 2012). The dynamic role of GABA:glutamate dysregulation and the interaction with normal development of this system in the evolution of drinking after TBI remains unspecified but deserves further attention.

\section{CONCLUDING REMARKS}

Alcohol use among adolescents is exceptionally common in western societies. Many individuals can drink heavily during this developmental period without developing AUD. However,

\section{REFERENCES}

Agrawal, R. G., Hewetson, A., George, C. M., Syapin, P. J., and Bergeson, S. E. (2011). Minocycline reduces ethanol drinking. Brain Behav. Immun. 25(Suppl. 1), S165-S169. doi: 10.1016/j.bbi.2011.03.002

Alfonso-Loeches, S., Pascual-Lucas, M., Blanco, A. M., Sanchez-Vera, I., and Guerri, C. (2010). Pivotal role of TLR4 receptors in alcoholinduced neuroinflammation and brain damage. J. Neurosci. 30, 8285-8295. doi: 10.1523/JNEUROSCI.0976-10.2010

Ates, O., Ondul, S., Onal, C., Buyukkiraz, M., Somay, H., Cayli, S. R., et al. (2006). Post-traumatic early epilepsy in pediatric age group with emphasis on influential factors. Child Nerv. Syst. 22, 279-284. doi: 10.1007/s00381-006-0171-y

Bales, J. W., Wagner, A. K., Kline, A. E., and Dixon, C. E. (2009). Persistent cognitive dysfunction after traumatic brain injury: a dopamine hypothesis. Neurosci. Biobehav. Rev. 33, 981-1003. doi: 10.1016/j.neubiorev.2009.03.011

Barnow, S., Schuckit, M. A., Lucht, M., John, U., and Freyberger, H. J. (2002). The importance of a positive family history of alcoholism, parental rejection and emotional warmth, behavioral problems and peer substance use for alcohol problems in teenagers: a path analysis. J. Stud. Alcohol 63, 305-315. doi: 10.15288/jsa.2002.63.305

Bechara, A., Damasio, A. R., Damasio, H., and Anderson, S. W. (1994). Insensitivity to future consequences following damage to human prefrontal cortex. Cognition 50, 7-15. doi: 10.1016/0010-0277(94)90018-3

Beresford, T. P., Arciniegas, D., Clapp, L., Martin, B., and Alfers, J. (2005). Reduction of affective lability and alcohol use following traumatic brain injury: a clinical pilot study of anti-convulsant medications. Brain Inj. 19, 309-313. doi: 10.1080/02699050410001720121

Bilbo, S. D., and Schwarz, J. M. (2009). Early-life programming of later-life brain and behavior: a critical role for the immune system. Front. Behav. Neurosci. 3:14. doi: 10.3389/neuro.08.014.2009

Bjork, J. M., and Grant, S. J. (2009). Does traumatic brain injury increase risk for substance abuse? J. Neurotrauma 26, 1077-1082. doi: 10.1089/neu.2008.0849

Blednov, Y. A., Benavidez, J. M., Geil, C., Perra, S., Morikawa, H., and Harris, R. A. (2011). Activation of inflammatory signaling by lipopolysaccharide produces a prolonged increase of voluntary alcohol intake in mice. Brain Behav. Immun. 25(Suppl. 1), S92-S105. doi: 10.1016/j.bbi.2011.01.008 patients with a history of TBI are much more likely to develop AUD. This is a major and critical public health problem because drinking after TBI can increase the risk of posttraumatic seizures, impair the efficacy of rehabilitation programs and increase the likelihood of subsequent TBI. The specific mechanisms that link TBI to AUD remain unspecified but it seems highly likely that it involves the coincidence of key psychosocial and neurochemical risk factors with important periods of neurological development. Targeting AUD in this population has the potential to significantly improve long-term outcomes.

\section{AUTHOR CONTRIBUTIONS}

All authors listed have made a substantial, direct and intellectual contribution to the work, and approved it for publication.

\section{FUNDING}

This work was supported by the Huron Foundation and the Ohio State University Wexner Medical Center Neuroscience Program. Additional support for behavioral experiments was provided by the National Institutes of Health (NINDS NS045758).

Blednov, Y. A., Ponomarev, I., Geil, C., Bergeson, S., Koob, G. F., and Harris, R. A. (2012). Neuroimmune regulation of alcohol consumption: behavioral validation of genes obtained from genomic studies. Addict. Biol. 17, 108-120. doi: 10.1111/j.1369-1600.2010.00284.x

Bolton, J. M., Robinson, J., and Sareen, J. (2009). Self-medication of mood disorders with alcohol and drugs in the National Epidemiologic Survey on Alcohol and Related Conditions. J. Affect. Disord. 115, 367-375. doi: 10.1016/j.jad.2008.10.003

Bombardier, C. H., Temkin, N. R., Machamer, J., and Dikmen, S. S. (2003). The natural history of drinking and alcohol-related problems after traumatic brain injury. Arch. Phys. Med. Rehabil. 84, 185-191. doi: 10.1053/apmr.2003.50002

Breslau, N., Davis, G. C., Andreski, P., and Peterson, E. (1991). Traumatic events and posttraumatic stress disorder in an urban population of young adults. Arch. Gen. Psychiatry 48, 216-222. doi: 10.1001/archpsyc.1991.01810270028003

Breslau, N., Davis, G. C., Peterson, E. L., and Schultz, L. (1997). Psychiatric sequelae of posttraumatic stress disorder in women. Arch. Gen. Psychiatry 54, 81-87. doi: 10.1001/archpsyc.1997.01830130087016

Bullock, R., Zauner, A., Woodward, J. J., Myseros, J., Choi, S. C., Ward, J. D., et al. (1998). Factors affecting excitatory amino acid release following severe human head injury. J. Neurosurg. 89, 507-518. doi: 10.3171/jns.1998.89.4.0507

Cantu, D., Walker, K., Andresen, L., Taylor-Weiner, A., Hampton, D., Tesco, G., et al. (2015). Traumatic brain injury increases cortical glutamate network activity by compromising GABAergic control. Cereb. Cortex 25, 2306-2320. doi: 10.1093/cercor/bhu041

Chandler, L. J. (2003). Ethanol and brain plasticity: receptors and molecular networks of the postsynaptic density as targets of ethanol. Pharmacol. Ther. 99, 311-326. doi: 10.1016/S0163-7258(03)00096-2

Chen, C. M., Yi, H.-Y., Yoon, Y.-H., and Dong, C. (2012). Alcohol use at time of injury and survival following traumatic brain injury: results from the National Trauma Data Bank. J. Stud. Alcohol Drugs 73, 531-541. doi: 10.15288/jsad.2012.73.531

Corrigan, J. D. (1995). Substance abuse as a mediating factor in outcome from traumatic brain injury. Arch. Phys. Med. Rehabil. 76, 302-309. doi: 10.1016/S0003-9993(95)80654-7

Corrigan, J. D., Bogner, J. A., Mysiw, W. J., Clinchot, D., and Fugate, L. (1997) Systematic bias in outcome studies of persons with traumatic brain injury. Arch. Phys. Med. Rehabil. 78, 132-137. doi: 10.1016/S0003-9993(97)90253-7 
Corrigan, J. D., Bogner, J., Mellick, D., Bushnik, T., Dams-O’Connor, K., Hammond, F. M., et al. (2013). Prior history of traumatic brain injury among persons in the traumatic brain injury model systems national database. Arch. Phys. Med. Rehabil. 94, 1940-1950. doi: 10.1016/j.apmr.2013.05.018

Corrigan, J. D., and Hammond, F. M. (2013). Traumatic brain injury as a chronic health condition. Arch. Phys. Med. Rehabil. 94, 1199-1201. doi: 10.1016/j.apmr.2013.01.023

Corrigan, J. D., and Mysiw, W. J. (2012). "Substance abuse among persons with TBI," in Brain Injury Medicine: Principles and Practice, 2nd Edn, eds N. D. Zasler, D. I. Katz, R. D. Zafonte, D. B. Arciniegas, M. R. Bullock, and J. S. Kreutzer (New York, NY: Demos Medical Publishing), 1315-1328.

Costello, E. J., Erkanli, A., Federman, E., and Angold, A. (1999). Development of psychiatric comorbidity with substance abuse in adolescents: effects of timing and sex. J. Clin. Child Psychol. 28, 298-311. doi: 10.1207/S15374424jccp280302

Crews, F. T., Zou, J., and Qin, L. (2011). Induction of innate immune genes in brain create the neurobiology of addiction. Brain Behav. Immun. 25, S4-S12. doi: 10.1016/j.bbi.2011.03.003

Cunnington, C., and Channon, K. M. (2010). Tetrahydrobiopterin: pleiotropic roles in cardiovascular pathophysiology. Heart 96, 1872-1877. doi: 10.1136/hrt.2009.180430

De Beaumont, L., Tremblay, S., Poirier, J., Lassonde, M., and Theoret, H. (2012). Altered bidirectional plasticity and reduced implicit motor learning in concussed athletes. Cereb. Cortex 22, 112-121. doi: 10.1093/cercor/bhr096

Ding, Y., Yao, B., Lai, Q., and McAllister, J. P. (2001). Impaired motor learning and diffuse axonal damage in motor and visual systems of the rat following traumatic brain injury. Neurol. Res. 23, 193-202. doi: $10.1179 / 016164101101198334$

Donnemiller, E., Brenneis, C., Wissel, J., Scherfler, C., Poewe, W., Riccabona, G., et al. (2000). Impaired dopaminergic neurotransmission in patients with traumatic brain injury: a SPECT study using 123I-beta-CIT and 123I-IBZM. Eur. J. Nucl. Med. 27, 1410-1414. doi: 10.1007/s002590000308

Dorsett, C. R., McGuire, J. L., DePasquale, E. A., Gardner, A. E., Floyd, C. L., and McCullumsmith, R. E. (2017). Glutamate neurotransmission in rodent models of traumatic brain injury. J. Neurotrauma 34, 263-272. doi: 10.1089/neu.2015.4373

Dube, S. R., Anda, R. F., Felitti, V. J., Croft, J. B., Edwards, V. J., and Giles, W. H. (2001). Growing up with parental alcohol abuse: exposure to childhood abuse, neglect, and household dysfunction. Child Abuse Negl. 25, 1627-1640. doi: 10.1016/S0145-2134(01)00293-9

Dunn-Meynell, A. A., and Levin, B. E. (1997). Histological markers of neuronal, axonal and astrocytic changes after lateral rigid impact traumatic brain injury. Brain Res. 761, 25-41. doi: 10.1016/S0006-8993(97)00210-2

Felger, J. C., and Miller, A. H. (2012). Cytokine effects on the basal ganglia and dopamine function: the subcortical source of inflammatory malaise. Front. Neuroendocrinol. 33, 315-327. doi: 10.1016/j.yfrne.2012.09.003

Fenn, A. M., Gensel, J. C., Huang, Y., Popovich, P. G., Lifshitz, J., and Godbout, J. P. (2014). Immune activation promotes depression 1 month after diffuse brain injury: a role for primed microglia. Biol. Psychiatry 76, 575-584. doi: 10.1016/j.biopsych.2013.10.014

Fishbein, D., Dariotis, J. K., Ferguson, P. L., and Pickelsimer, E. E. (2016). Relationships between traumatic brain injury and illicit drug use and their association with aggression in inmates. Int. J. Offender Ther. Comp. Criminol. 60, 575-597. doi: 10.1177/0306624X14554778

Fitzgerald, G. J., Liu, H., and Morzorati, S. L. (2012). Decreased sensitivity of NMDA receptors on dopaminergic neurons from the posterior ventral tegmental area following chronic nondependent alcohol consumption. Alcohol. Clin. Exp. Res. 36, 1710-1719. doi: 10.1111/j.1530-0277.2012.01 762.x

Giza, C. C., Kutcher, J. S., Ashwal, S., Barth, J., Getchius, T. S., Gioia, G. A., et al. (2013). Summary of evidence-based guideline update: evaluation and management of concussion in sports: report of the Guideline Development Subcommittee of the American Academy of Neurology. Neurology 80, 2250-2257. doi: 10.1212/WNL.0b013e31828d57dd

Giza, C. C., and Prins, M. L. (2006). Is being plastic fantastic? Mechanisms of altered plasticity after developmental traumatic brain injury. Dev Neurosci. 28, 364-379. doi: 10.1159/000094163

Glang, A., Todis, B., Cooley, E., Wells, J., and Voss, J. (1997). Building social networks for children and adolescents with traumatic brain injury: a school-based intervention. J. Head Trauma Rehabil. 12, 32-47. doi: 10.1097/00001199-199704000-00005

Goldman, M. S. (1994). The alcohol expectancy concept: applications to assessment, prevention, and treatment of alcohol abuse. Appl. Prevent. Psychol. 3, 131-144. doi: 10.1016/S0962-1849(05)80066-6

Graham, D. P., and Cardon, A. L. (2008). An update on substance use and treatment following traumatic brain injury. Ann. N.Y. Acad. Sci. 1141, 148-162. doi: 10.1196/annals.1441.029

Grant, B. F., and Dawson, D. A. (1997). Age at onset of alcohol use and its association with DSM-IV alcohol abuse and dependence: results from the national longitudinal alcohol epidemiologic survey. J. Subst. Abuse 9, 103-110. doi: 10.1016/S0899-3289(97)90009-2

Grant, B. F., and Dawson, D. A. (1998). Age of onset of drug use and its association with DSM-IV drug abuse and dependence: results from the National Longitudinal Alcohol Epidemiologic Survey. J. Subst. Abuse 10, 163-173. doi: 10.1016/S0899-3289(99)80131-X

Guerri, C., and Pascual, M. (2010). Mechanisms involved in the neurotoxic, cognitive, and neurobehavioral effects of alcohol consumption during adolescence. Alcohol 44, 15-26. doi: 10.1016/j.alcohol.2009.10.003

Guskiewicz, K. M., Weaver, N. L., Padua, D. A., and Garrett, W. E. Jr. (2000). Epidemiology of concussion in collegiate and high school football players. Am. J. Sports Med. 28, 643-650. doi: 10.1177/03635465000280050401

He, J., and Crews, F. T. (2008). Increased MCP-1 and microglia in various regions of the human alcoholic brain. Exp. Neurol. 210, 349-358. doi: 10.1016/j.expneurol.2007.11.017

Huang, C. H., Huang, C. C., Sun, C. K., Lin, G. H., and Hou, W. H. (2016). Methylphenidate on cognitive improvement in patients with traumatic brain injury: a meta-analysis. Curr. Neuropharmacol. 14, 272-281. doi: 10.2174/1570159X13666150514233033

Hutson, C. B., Lazo, C. R., Mortazavi, F., Giza, C. C., Hovda, D., and Chesselet, M. F. (2011). Traumatic brain injury in adult rats causes progressive nigrostriatal dopaminergic cell loss and enhanced vulnerability to the pesticide paraquat. $J$. Neurotrauma 28, 1783-1801. doi: 10.1089/neu.2010.1723

Iacono, W. G., Malone, S. M., and McGue, M. (2008). Behavioral disinhibition and the development of early-onset addiction: common and specific influences. Annu. Rev. Clin. Psychol. 4, 325-348. doi: 10.1146/annurev.clinpsy.4.022007.141157

Ilie, G., Mann, R. E., Hamilton, H., Adlaf, E. M., Boak, A., Asbridge, M., et al. (2015). Substance use and related harms among adolescents with and without traumatic brain injury. J. Head Trauma Rehabil. 30, 293-301. doi: 10.1097/HTR.0000000000000101

Johnson, V. E., Stewart, J. E., Begbie, F. D., Trojanowski, J. Q., Smith, D. H., and Stewart, W. (2013). Inflammation and white matter degeneration persist for years after a single traumatic brain injury. Brain 136(Pt 1), 28-42. doi: 10.1093/brain/aws322

Jorge, R. E., Robinson, R. G., Moser, D., Tateno, A., Crespo-Facorro, B., and Arndt, S. (2004). Major depression following traumatic brain injury. Arch. Gen. Psychiatry 61, 42-50. doi: 10.1001/archpsyc.61.1.42

Juengst, S. B., Kumar, R. G., Failla, M. D., Goyal, A., and Wagner, A. K. (2015). Acute inflammatory biomarker profiles predict depression risk following moderate to severe traumatic brain injury. J. Head Trauma Rehabil. 30, 207-218. doi: 10.1097/HTR.0000000000000031

Karelina, K., Gaier, K. R., Prabhu, M., Wenger, V., Corrigan, T. E., and Weil, Z. M. (2017). Binge ethanol in adulthood exacerbates negative outcomes following juvenile traumatic brain injury. Brain Behav. Immun. 60, 304-311. doi: 10.1016/j.bbi.2016.11.009

Katayama, Y., Becker, D. P., Tamura, T., and Hovda, D. A. (1990). Massive increases in extracellular potassium and the indiscriminate release of glutamate following concussive brain injury. J. Neurosurg. 73, 889-900. doi: $10.3171 /$ jns. 1990.73 .6 .0889

Keenan, H. T., and Bratton, S. L. (2006). Epidemiology and outcomes of pediatric traumatic brain injury. Dev. Neurosci. 28, 256-263. doi: 10.1159/000094152

Kelley, B. J., Lifshitz, J., and Povlishock, J. T. (2007). Neuroinflammatory responses after experimental diffuse traumatic brain injury. J. Neuropathol. Exp. Neurol. 66, 989-1001. doi: 10.1097/NEN.0b013e3181588245

Kelley, K. W., and Dantzer, R. (2011). Alcoholism and inflammation: neuroimmunology of behavioral and mood disorders. Brain Behav. Immun. 25(Suppl. 1), S13-S20. doi: 10.1016/j.bbi.2010.12.013 
King, S. M., Iacono, W. G., and McGue, M. (2004). Childhood externalizing and internalizing psychopathology in the prediction of early substance use. Addiction 99, 1548-1559. doi: 10.1111/j.1360-0443.2004.00893.x

Kolitz, B. P., Vanderploeg, R. D., and Curtiss, G. (2003). Development of the Key Behaviors Change Inventory: a traumatic brain injury behavioral outcome assessment instrument. Arch. Phys. Med. Rehabil. 84, 277-284. doi: 10.1053/apmr.2003.50100

Koob, G. F., and Volkow, N. D. (2016). Neurobiology of addiction: a neurocircuitry analysis. Lancet Psychiatry 3, 760-773. doi: 10.1016/S2215-0366(16)00104-8

Kraus, J. F., Morgenstern, H., Fife, D., Conroy, C., and Nourjah, P. (1989). Bloodalcohol tests, prevalence of involvement, and outcomes following brain injury. Am. J. Public Health 79, 294-299. doi: 10.2105/AJPH.79.3.294

Kreutzer, J. S., Witol, A. D., and Marwitz, J. H. (1996). Alcohol and drug use among young persons with traumatic brain injury. J. Learn. Disabil. 29, 643-651. doi: $10.1177 / 002221949602900608$

Laucht, M., Becker, K., Blomeyer, D., and Schmidt, M. H. (2007). Novelty seeking involved in mediating the association between the dopamine D4 receptor gene exon III polymorphism and heavy drinking in male adolescents: results from a high-risk community sample. Biol. Psychiatry 61, 87-92. doi: 10.1016/j.biopsych.2006.05.025

Leclercq, S., De Saeger, C., Delzenne, N., de Timary, P., and Starkel, P. (2014). Role of inflammatory pathways, blood mononuclear cells, and gutderived bacterial products in alcohol dependence. Biol. Psychiatry 76, 725-733. doi: 10.1016/j.biopsych.2014.02.003

Lim, Y. W., Meyer, N. P., Shah, A. S., Budde, M. D., Stemper, B. D., and Olsen, C. M. (2015). Voluntary alcohol intake following blast exposure in a rat model of mild traumatic brain injury. PLOS ONE 10:e0125130. doi: 10.1371/journal.pone.0125130

Lowing, J. L., Susick, L. L., Caruso, J. P., Provenzano, A. M., Raghupathi, R., and Conti, A. C. (2014). Experimental traumatic brain injury alters ethanol consumption and sensitivity. J. Neurotrauma 31, 1700-1710. doi: $10.1089 /$ neu.2013.3286

Maggs, J. L., Patrick, M. E., and Feinstein, L. (2008). Childhood and adolescent predictors of alcohol use and problems in adolescence and adulthood in the National Child Development Study. Addiction 103, 7-22. doi: 10.1111/j.1360-0443.2008.02173.x

Martinez, D., Gil, R., Slifstein, M., Hwang, D.-R., Huang, Y., Perez, A., et al. (2005). Alcohol dependence is associated with blunted dopamine transmission in the ventral striatum. Biol. Psychiatry 58, 779-786. doi: 10.1016/j.biopsych.2005.04.044

Masel, B. E., and DeWitt, D. S. (2010). Traumatic brain injury: a disease process, not an event. J. Neurotrauma 27, 1529-1540. doi: 10.1089/neu.2010.1358

Mayeux, J. P., Teng, S. X., Katz, P. S., Gilpin, N. W., and Molina, P. E. (2015). Traumatic brain injury induces neuroinflammation and neuronal degeneration that is associated with escalated alcohol self-administration in rats. Behav. Brain Res. 279, 22-30. doi: 10.1016/j.bbr.2014.10.053

McCrory, P., Meeuwisse, W. H., Aubry, M., Cantu, B., Dvorak, J., Echemendia, R. J., et al. (2013). Consensus statement on concussion in sport: the 4th International Conference on Concussion in Sport held in Zurich, November 2012. Br. J. Sports Med. 47, 250-258. doi: 10.1136/bjsports-2013-092313

McCutcheon, J. E., Conrad, K. L., Carr, S. B., Ford, K. A., McGehee, D. S., and Marinelli, M. (2012). Dopamine neurons in the ventral tegmental area fire faster in adolescent rats than in adults. J. Neurophysiol. 108, 1620-1630. doi: $10.1152 /$ jn. 00077.2012

McKinlay, A., Corrigan, J., Horwood, L. J., and Fergusson, D. M. (2014). Substance abuse and criminal activities following traumatic brain injury in childhood, adolescence, and early adulthood. J. Head Trauma Rehabil. 29, 498-506. doi: 10.1097/HTR.0000000000000001

Merkel, S. F., Cannella, L. A., Razmpour, R., Lutton, E., Raghupathi, R., Rawls, S. M., et al. (2017a). Factors affecting increased risk for substance use disorders following traumatic brain injury: what we can learn from animal models. Neurosci. Biobehav. Rev. 77, 209-218. doi: 10.1016/j.neubiorev.2017.03.015

Merkel, S. F., Razmpour, R., Lutton, E. M., Tallarida, C. S., Heldt, N. A., Cannella, L. A., et al. (2017b). Adolescent traumatic brain injury induces chronic mesolimbic neuroinflammation with concurrent enhancement in the rewarding effects of cocaine in mice during adulthood. J. Neurotrauma 34, 165-181. doi: 10.1089/neu.2015.4275
Narang, S., and Clarke, J. (2014). Abusive head trauma: past, present, and future. J. Child Neurol. 29, 1747-1756. doi: 10.1177/0883073814549995

Neurobehavioral Guidelines Working, G., Warden, D. L., Gordon, B., McAllister, T. W., Silver, J. M., Barth, J. T., et al. (2006). Guidelines for the pharmacologic treatment of neurobehavioral sequelae of traumatic brain injury. J. Neurotrauma 23, 1468-1501. doi: 10.1089/neu.2006.23.1468

Ono, K., Suzuki, H., and Sawada, M. (2010). Delayed neural damage is induced by iNOS-expressing microglia in a brain injury model. Neurosci. Lett. 473, 146-150. doi: 10.1016/j.neulet.2010.02.041

Opreanu, R. C., Kuhn, D., and Basson, M. D. (2010). Influence of alcohol on mortality in traumatic brain injury. J. Am. Coll. Surg. 210, 997-1007. doi: 10.1016/j.jamcollsurg.2010.01.036

Pascual, M., Fernandez-Lizarbe, S., and Guerri, C. (2011). Role of TLR4 in ethanol effects on innate and adaptive immune responses in peritoneal macrophages. Immunol. Cell Biol. 89, 716-727. doi: 10.1038/icb.2010.163

Pavlov, I., Huusko, N., Drexel, M., Kirchmair, E., Sperk, G., Pitkanen, A., et al. (2011). Progressive loss of phasic, but not tonic, gaba(a) receptor-mediated inhibition in dentate granule cells in a model of post-traumatic epilepsy in rats. Neuroscience 194, 208-219. doi: 10.1016/j.neuroscience.2011.07.074

Philpot, R. M., Wecker, L., and Kirstein, C. L. (2009). Repeated ethanol exposure during adolescence alters the developmental trajectory of dopaminergic output from the nucleus accumbens septi. Int. J. Dev. Neurosci. 27, 805-815. doi: 10.1016/j.ijdevneu.2009.08.009

Ponsford, J., Whelan-Goodinson, R., and Bahar-Fuchs, A. (2007). Alcohol and drug use following traumatic brain injury: a prospective study. Brain Inj. 21, 1385-1392. doi: 10.1080/02699050701796960

Savola, O., Niemela, O., and Hillbom, M. (2005). Alcohol intake and the pattern of trauma in young adults and working aged people admitted after trauma. Alcohol Alcohol. 40, 269-273. doi: 10.1093/alcalc/agh159

Schwarzbach, E., Bonislawski, D. P., Xiong, G., and Cohen, A. S. (2006). Mechanisms underlying the inability to induce area CA1 LTP in the mouse after traumatic brain injury. Hippocampus 16, 541-550. doi: 10.1002/hipo.20183

Smedema, S. M., and Ebener, D. (2010). Substance abuse and psychosocial adaptation to physical disability: analysis of the literature and future directions. Disabil. Rehabil. 32, 1311-1319. doi: 10.3109/09638280903514721

Stewart-Scott, A. M., and Douglas, J. M. (1998). Educational outcome for secondary and postsecondary students following traumatic brain injury. Brain Inj. 12, 317-331. doi: 10.1080/026990598122629

Stoduto, G., Vingilis, E., Kapur, B. M., Sheu, W. J., Mclellan, B. A., and Liban, C. B. (1993). Alcohol and drug-use among motor-vehicle collision victims admitted to a regional trauma unit - demographic, injury, and crash characteristics. Accid. Anal. Prev. 25, 411-420. doi: 10.1016/0001-4575(93)90070-D

Unsworth, D. J., and Mathias, J. L. (2017). Traumatic brain injury and alcohol/substance abuse: a Bayesian meta-analysis comparing the outcomes of people with and without a history of abuse. J. Clin. Exp. Neuropsychol. 39, 547-562. doi: 10.1080/13803395.2016.1248812

Vaaramo, K., Puljula, J., Tetri, S., Juvela, S., and Hillbom, M. (2014). Head trauma sustained under the influence of alcohol is a predictor for future traumatic brain injury: a long-term follow-up study. Eur. J. Neurol. 21, 293-298. doi: 10.1111/ene.12302

Valles, S. L., Blanco, A. M., Pascual, M., and Guerri, C. (2004). Chronic ethanol treatment enhances inflammatory mediators and cell death in the brain and in astrocytes. Brain Pathol. 14, 365-371. doi: 10.1111/j.1750-3639.2004.tb00079.x

Wagner, A. K., Chen, X., Kline, A. E., Li, Y., Zafonte, R. D., and Dixon, C. E. (2005a). Gender and environmental enrichment impact dopamine transporter expression after experimental traumatic brain injury. Exp. Neurol. 195, 475-483. doi: 10.1016/j.expneurol.2005.06.009

Wagner, A. K., Drewencki, L. L., Chen, X., Santos, F. R., Khan, A. S., Harun, R., et al. (2009). Chronic methylphenidate treatment enhances striatal dopamine neurotransmission after experimental traumatic brain injury. J. Neurochem. 108, 986-997. doi: 10.1111/j.1471-4159.2008.05840.x

Wagner, A. K., Sokoloski, J. E., Ren, D., Chen, X., Khan, A. S., Zafonte, R. D., et al. (2005b). Controlled cortical impact injury affects dopaminergic transmission in the rat striatum. J. Neurochem. 95, 457-465. doi: 10.1111/j.1471-4159.2005.03382.x

Wahlstrom, D., Collins, P., White, T., and Luciana, M. (2010). Developmental changes in dopamine neurotransmission in adolescence: behavioral 
implications and issues in assessment. Brain Cogn. 72, 146-159. doi: 10.1016/j.bandc.2009.10.013

Weil, Z. M., Corrigan, J. D., and Karelina, K. (2016a). Alcohol abuse after traumatic brain injury: experimental and clinical evidence. Neurosci. Biobehav. Rev. 62, 89-99. doi: 10.1016/j.neubiorev.2016.01.005

Weil, Z. M., Karelina, K., Gaier, K. R., Corrigan, T. E., and Corrigan, J. D. (2016b). Juvenile traumatic brain injury increases alcohol consumption and reward in female mice. J. Neurotrauma 33, 895-903. doi: 10.1089/neu.2015.3953

Werner, C., and Engelhard, K. (2007). Pathophysiology of traumatic brain injury. Br. J. Anaesth. 99, 4-9. doi: 10.1093/bja/aem131

Yan, H. Q., Kline, A. E., Ma, X., Hooghe-Peters, E. L., Marion, D. W., and Dixon, C. E. (2001). Tyrosine hydroxylase, but not dopamine beta-hydroxylase, is increased in rat frontal cortex after traumatic brain injury. Neuroreport 12, 2323-2327. doi: 10.1097/00001756-200108080-00009

Yan, H. Q., Kline, A. E., Ma, X., Li, Y., and Dixon, C. E. (2002). Traumatic brain injury reduces dopamine transporter protein expression in the rat frontal cortex. Neuroreport 13, 1899-1901. doi: 10.1097/00001756-200210280-00013

Yen, C. H., Ho, P. S., Yeh, Y. W., Liang, C. S., Kuo, S. C., Huang, C. C., et al. (2017).
Differential cytokine levels between early withdrawal and remission states in patients with alcohol dependence. Psychoneuroendocrinology 76, 183-191. doi: 10.1016/j.psyneuen.2016.10.015

Ziebell, J. M., and Morganti-Kossmann, M. C. (2010). Involvement of pro- and anti-inflammatory cytokines and chemokines in the pathophysiology of traumatic brain injury. Neurotherapeutics 7, 22-30. doi: 10.1016/j.nurt.2009.10.016

Conflict of Interest Statement: The authors declare that the research was conducted in the absence of any commercial or financial relationships that could be construed as a potential conflict of interest.

Copyright (c) 2017 Weil and Karelina. This is an open-access article distributed under the terms of the Creative Commons Attribution License (CC BY). The use, distribution or reproduction in other forums is permitted, provided the original author(s) or licensor are credited and that the original publication in this journal is cited, in accordance with accepted academic practice. No use, distribution or reproduction is permitted which does not comply with these terms. 